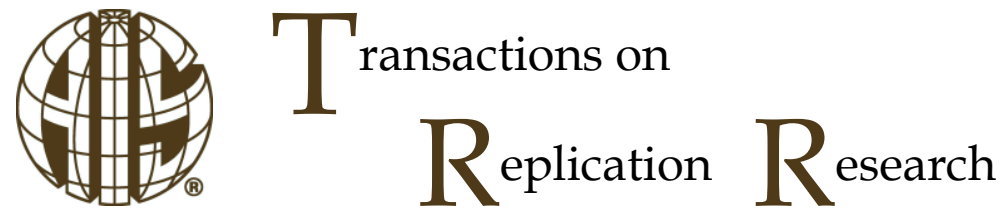

\section{Involuntary Embarrassing Exposures in Online Social Networks: A Replication Study}

Mohammadreza Ebrahimi

Department of Management Information Systems, Eller College of Management, University of Arizona, USA ebrahimi@email.arizona.edu

\section{J. Daniel Martinez}

Department of Marketing, Eller College of Management, University of Arizona, USA

jdmartinez@email.arizona.edu

Abstract:

In this study, we carry out a methodological replication of the research done by Choi et al. (2015) published in Information System Research. In the original study, the authors integrate the privacy and teasing literatures under a social exchange framework to understand online involuntary exposures. The original study was conducted on students from Southeast Asia. Our study uses a significantly larger sample of college students in the United States. Our replication results show that whereas most of the hypotheses supported by the original results on behavioral responses replicate with high consistency (8 out of 12 hypotheses), the results that deal with the effects of network commonality on perceived privacy invasion and perceived relationship bonding did not replicate (4 out of 12 hypotheses). These results could stem from a failed manipulation of network commonality. We look into the possible rationales for this and show what would be an effective manipulation in our context. Further, we expand the original study by testing an additional embarrassing scenario catered to our subject pool. The results suggest that perceived privacy invasion and perceived relationship bonding affect individual's behavioral responses to embarrassing exposures.

Keywords: Online social networks, Embarrassing exposure, Privacy invasion, Relationship bonding, Inaction, Avoidance behavior, Approach behavior, Replication 


\section{Introduction}

Online social networks have been used extensively since the last decade. Users go to online social networks to maintain, nourish, or start relationships with other users around the world. These connections are valuable for both the users and the online platform. While useful and benign information is shared on these sites, sometimes embarrassing information about individuals is also disseminated through them (Wang et al., 2011). The market value of online social networks such as Facebook depends highly on the benign interactions between their members (Smith, 2013). Therefore, when users forgo the use of the online platforms in response to an involuntary exposure, this has significant financial implications for social network companies. The value that these sites offer to sponsors, advertisers, and buyers is the access to the users' network connections and information sharing. Therefore, social network platforms rely heavily on maintaining channels with favorable relationships amongst their users.

In their original study, Choi et al. (2015) integrated the privacy literature and the teasing literature under a social exchange theory framework to better understand online involuntary exposures. The authors focused on the behavioral attribute of an exchange and the structural attribute of exchange networks. The behavioral attribute refers to the communication actions people use in the social exchange. The original study focused on two kinds of actions based around information dissemination, or how the embarrassing exposure is shared with a network. These two exchange behaviors are posting only and posting with tagging. In these exchanges, a disseminator posts an embarrassing message about someone else (e.g., the target) and decides whether to tag the target user. The structure of social relationships is defined as the way in which the information networks are configured. To operationalize this concept, the authors looked at how much overlap exists between an information disseminator's network and the target's network. High overlap, or high network commonality, suggests strongly and tightly bound relationships between actors. Low network commonality suggests a sparser network in which the actors tend to have relatively independent social circles. The authors showed that there is an interaction between information dissemination and network commonality, which affects perceived privacy invasion and perceived relationship bonding. The authors propose that perceived privacy invasion is the biggest cost target users face in an involuntary embarrassing exposure situation. In other words, the degree to which a person feels her space is intruded on by others is the biggest cost for the target actor in an exchange. However, individuals might gain an improved social relationship as a benefit of the involuntary exposure if the target user construes the event as friendly teasing (e.g., increasing perceived relationship bonding). The authors also showed that perceived privacy invasion and perceived relationship bonding affect the individual's response to embarrassing exposures and characterize the possible responses.

In this replication study, we look at the effects of embarrassing exposures in online social networks on the assessment of social exchanges and user behavior. We replicate the study proposed by Choi et al. (2015) in which the authors show that network commonality and information dissemination influence the way users perceive privacy invasion and relationship bonding when encountering an embarrassing online post. The authors also show that differences in perceived privacy invasion and relationship bonding affect the target user's behavioral response on social media platforms. We are interested in exploring the effects presented by the authors in a different context. To this end, we use a pool of American students from a large southwest university to conduct our study on a sample of 266 participants, almost twice the sample size in the original study. Consistent with the original paper we use their proposed scenario as embarrassing stimulus. However, we enrich our replication by adding an additional scenario based on the idea of "heavy drinking on a Friday night". The scenario is not only significantly more embarrassing but also relevant to American undergraduate students.

The conceptual model used by Choi et al. (Choi, Jiang, Xiao, \& Kim, 2015) is presented in Figure 1. 




Figure 1. The research model for involuntary embarrassing behavior exposure in social media (Choi et al., 2015)

We operationalize information dissemination and network commonality based on the original study. Information dissemination is represented as the way the disseminating user opts to propagate the information in a social network (e.g., Facebook). Consistent with the original study, these actions can be posting with tagging or posting without tagging. Network commonality is operationalized as the number of common friends between the user who posts the embarrassing content and the target user. These two variables are theorized to affect the perception the target user has about privacy invasion and relationship bonding and are therefore manipulated in the original study. The target of the embarrassing post might feel her privacy has been invaded by the embarrassing post or might construe the post as a benign violation that improves her social relationship with the disseminator.

As in the original paper, we measure perceived privacy invasion and perceived relationship bonding. We also record the behavioral responses revealed by the participants after being exposed to a hypothetic scenario, consistent with the original study. Additionally, the authors measured dispositional privacy concerns, sociability, Facebook familiarity, and Facebook usage intensity as control variables. Consistent with their original framework and design, we measured all the constructs previously mentioned, except for Facebook familiarity. We removed the Facebook familiarity measurement because we ensured that all students in the sample used Facebook. However, we kept measures such as the 'Facebook usage intensity' to distinguish between students who use Facebook more frequently than the others. It is worth mentioning that the Facebook penetration in US is significantly higher than in Asia. In fact, as of June $30^{\text {th }}, 2016$ the penetration of Facebook in North America is 62\%, compared to an approximate 13\% penetration rate in Asia (Internet World Stats, 2017). This difference significantly increases when the sample is taken from undergraduate students, as is the case for both the original study and the current replication.

Our replication aims to evaluate all 12 hypotheses stated in the original paper. A summary of the hypotheses from the original paper is presented in Table 1. 


\begin{tabular}{|c|c|c|c|}
\hline \multicolumn{4}{|c|}{ Table 1. Hypotheses Stated in the Original Study along with Involved Variables } \\
\hline \multirow[b]{2}{*}{ Hypothesis No. } & \multirow[b]{2}{*}{ Hypothesis } & \multicolumn{2}{|c|}{ Involved variables } \\
\hline & & IV & DV \\
\hline $\mathrm{H} 1 \mathrm{~A}$ & $\begin{array}{l}\text { Compared with posting only, posting with tagging } \\
\text { will lead to a higher level of perceived privacy } \\
\text { invasion. }\end{array}$ & $\begin{array}{l}\text { Information } \\
\text { dissemination }\end{array}$ & \multirow[b]{2}{*}{ Privacy Invasion } \\
\hline H1B & $\begin{array}{l}\text { The effect of information dissemination on } \\
\text { perceived privacy invasion is stronger in the low } \\
\text { network commonality condition than in the high } \\
\text { network commonality condition. }\end{array}$ & $\begin{array}{l}\text { Information } \\
\text { dissemination } \\
\text { Network } \\
\text { commonality }\end{array}$ & \\
\hline $\mathrm{H} 2 \mathrm{~A}$ & $\begin{array}{l}\text { In the low network commonality condition, } \\
\text { compared with posting only, posting with tagging } \\
\text { will lead to a lower level of perceived relationship } \\
\text { bonding. }\end{array}$ & \multirow{2}{*}{$\begin{array}{l}\text { Information } \\
\text { dissemination } \\
\text { Network } \\
\text { commonality }\end{array}$} & \multirow{2}{*}{$\begin{array}{l}\text { Relationship } \\
\text { Bonding }\end{array}$} \\
\hline $\mathrm{H} 2 \mathrm{~B}$ & $\begin{array}{l}\text { In the high network commonality condition, } \\
\text { compared with posting only, posting with tagging } \\
\text { will lead to a higher level of perceived relationship } \\
\text { bonding. }\end{array}$ & & \\
\hline H3A & $\begin{array}{l}\text { Perceived privacy invasion will reduce the } \\
\text { likelihood of inaction. }\end{array}$ & \multirow{4}{*}{ Privacy Invasion } & \multirow{4}{*}{$\begin{array}{l}\text { Behavioral } \\
\text { Response }\end{array}$} \\
\hline H3B & $\begin{array}{l}\text { Perceived privacy invasion will increase the } \\
\text { likelihood of transactional avoidance. }\end{array}$ & & \\
\hline $\mathrm{H} 3 \mathrm{C}$ & $\begin{array}{l}\text { Perceived privacy invasion will increase the } \\
\text { likelihood of interpersonal avoidance. }\end{array}$ & & \\
\hline H3D & $\begin{array}{l}\text { Perceived privacy invasion will reduce the } \\
\text { likelihood of approach behavior. }\end{array}$ & & \\
\hline $\mathrm{H} 4 \mathrm{~A}$ & $\begin{array}{l}\text { Perceived relationship bonding will reduce the } \\
\text { likelihood of inaction. }\end{array}$ & \multirow{4}{*}{$\begin{array}{l}\text { Relationship } \\
\text { Bonding }\end{array}$} & \multirow{4}{*}{$\begin{array}{l}\text { Behavioral } \\
\text { Response }\end{array}$} \\
\hline H4B & $\begin{array}{l}\text { Perceived relationship bonding will reduce the } \\
\text { likelihood of transactional avoidance. }\end{array}$ & & \\
\hline $\mathrm{H} 4 \mathrm{C}$ & $\begin{array}{l}\text { Perceived relationship bonding will reduce the } \\
\text { likelihood of interpersonal avoidance. }\end{array}$ & & \\
\hline $\mathrm{H} 4 \mathrm{D}$ & $\begin{array}{l}\text { Perceived relationship bonding will increase the } \\
\text { likelihood of approach behavior. }\end{array}$ & & \\
\hline
\end{tabular}

\section{Research Method}

This paper is a methodological replication of (Choi et al., 2015) in which we used a scenario-based survey experiment using the $2 \times 2$ factorial design consistent with the experiment presented in the original study. We used the same scenarios and manipulations used in the original study. We expand on the original study by introducing a new embarrassing scenario and implementing the network commonality and information dissemination manipulations accordingly. Adding a new scenario creates an additional condition that expands the original $2 \times 2$ study to an experiment with two independent $2 \times 2$ designs. The original study employs 109 students from a Southeast Asian university. For our study, we recruited 266 business school students from a large American Southwest university. We randomly assigned the participants to one of the eight conditions as shown in Table 2. 


\begin{tabular}{|c|c|c|}
\hline$\overline{T a b l}$ & r conaition & \\
\hline Experimental Condi & the Original Study & \\
\hline & Low network commonality & High network commonality \\
\hline Posting only & $\mathrm{n}=27$ & $\mathrm{n}=28$ \\
\hline Posting with tagging & $\mathrm{n}=28$ & $n=26$ \\
\hline Experimental condi & sleeping stimuli in the $R$ & cation Study \\
\hline & Low network commonality & High network commonality \\
\hline Posting only & $\mathrm{n}=40$ & $n=20$ \\
\hline Posting with tagging & $\mathrm{n}=35$ & $\mathrm{n}=41$ \\
\hline Experimental condi & drinking stimuli in the $R$ & cation Study \\
\hline & Low network commonality & High network commonality \\
\hline Posting only & $\mathrm{n}=42$ & $n=34$ \\
\hline Posting with tagging & $\mathrm{n}=28$ & $n=26$ \\
\hline
\end{tabular}

The original study presents students with one of four hypothetical situations in which a friend of theirs posts an embarrassing description of them sleeping in lecture. Consistent with (Choi et al., 2015) we used the same wording employed in the original scenarios, and included the same manipulations for network commonality and information dissemination. High (low) network commonality scenarios present students with a situation where they share 65 (7) common friends in the Facebook platform. Posting with tagging (posting only) scenarios present students with situations where they have (have not) been tagged in the embarrassing post by their hypothetical friend. As expressed before, we included a new scenario based on uncontrolled drinking leading to an embarrassing speech at a local bar. This scenario was included in our replication because we were unsure that sleeping in lecture would be considered as embarrassing for undergraduate students in the USA, compared to students in Southeast Asia. This only affected the wording of the posted note included in the scenario and the scenario's setup story; all other instructions, manipulations, and graphics presented were kept constant.

In their experiment, Choi et al. (2015) developed a web application that mimicked the Facebook environment and allowed participants to interact with it just as if they were in the actual social media platform. In our study, we present participants with a scenario via text descriptions and include screen captures representing the hypothetical case with which they were presented. Figures 2, 3, and 4 present the graphic examples of the actual scenarios presented to participants in the survey. The Facebook screenshots are based on the platform's look and feel at the time this survey was conducted, rather than the look and feel employed in the original paper. A gender-neutral name (Sam X) was used in all scenarios to avoid gender bias. The online survey was distributed using Qualtrics survey software. Participants were randomly assigned to one of the eight treatment conditions, four conditions for the sleeping in class scenario and four conditions for the drinking scenario. Participants were then asked to carefully read the scenario presented to them. Next, participants were given the opportunity to react to the embarrassing post by selecting one or more of the response options included in the original paper via a multiple-choice question. The response options were presented in random order. The text of each option as well as the response type to which they were coded following Choi et al. (2015) are shown in Table 3. 


\begin{tabular}{|c|c|c|}
\hline \multicolumn{3}{|c|}{$\begin{array}{l}\text { Instruction: Please select the probable action(s) that you might take on your Facebook after reading this } \\
\text { post. You may choose multiple options. }\end{array}$} \\
\hline Question Item & Response Type & Graphical instrument \\
\hline $\begin{array}{l}\text { I would do nothing about Sam's post on my } \\
\text { Facebook. }\end{array}$ & Inaction & Checkbox \\
\hline I would 'unfriend' Sam from my Facebook. & Interpersonal avoidance & Checkbox \\
\hline I would 'like' Sam's post. & Approach & Checkbox \\
\hline I would 'report' Sam on Facebook. & Interpersonal avoidance & Checkbox \\
\hline I would 'love' Sam's post. & Approach & Checkbox \\
\hline I would 'block' Sam on my Facebook. & Interpersonal avoidance & Checkbox \\
\hline $\begin{array}{l}\text { I would share Sam's post to other friends on } \\
\text { Facebook. }\end{array}$ & Approach & Checkbox \\
\hline $\begin{array}{l}\text { I would comment on Sam's post. (Please type your } \\
\text { comment on the box provided) }\end{array}$ & \multirow{2}{*}{$\begin{array}{l}\text { Avoidance or Approach } \\
\text { (Depending on the } \\
\text { comment's text) }\end{array}$} & Checkbox and Textbox. \\
\hline $\begin{array}{l}\text { Send inbox or private message. (Please type your } \\
\text { message on the box provided) }\end{array}$ & & Checkbox and Textbox. \\
\hline
\end{tabular}

As seen in Table 3, in order to mimic the experimental platform in the original study, the participant is required to type the actual Facebook comments and Facebook messages they would post in response. This simulates the social media mechanism in which only by actually typing a message the user either comments on a post or directly messages another user. By typing the message and submitting it, the participants are engaging in all the relevant decision-making processes of responding to a post, not only saying they would comment but also writing what the comment would be. We coded every textual answer (messages or comments) to determine its type of behavioral response in a manner consistent with the original study.

Subsequently, participants answered questions related to the constructs in the research model, and control variables. This study used the same measurements as in (Choi et al., 2015). As in with the original study, we assessed the embarrassment and relevance of the scenarios in the survey using the embarrassment and relevance scales proposed by Choi et al. (Choi et al., 2015). Although our means for both embarrassment and relevance are not as high as in the original study, our drinking scenario is significantly more embarrassing and relevant to our sample than the original sleeping scenario $(p<0.01$ for both independent sample T-tests). Means and standard deviation for these measures are presented in Table 4.

Table 4. Means of Responses for Perceived Embarrassment and Relevance (Original and Replication)

\begin{tabular}{|l|l|l|}
\hline Original Study & \multicolumn{2}{l|}{} \\
\hline Variable & Mean & Std. Dev. \\
\hline Perc. Embarrassment & 6.28 & 0.69 \\
\hline Perc. Relevance & 6.03 & 0.73 \\
\hline Drinking scenario & \multicolumn{2}{|l|}{} \\
\hline Variable & Mean & Std. Dev. \\
\hline Perc. Embarrassment & 5.98 & 1.10 \\
\hline Perc. Relevance & 5.79 & 1.22 \\
\hline Sleeping scenario & Mean & Std. Dev. \\
\hline Variable & 4.70 & 1.55 \\
\hline Perc. Embarrassment & 4.40 & 1.59 \\
\hline Perc. Relevance &
\end{tabular}

\section{Results}

\subsection{Descriptive Statistics}

Of the 266 participants, 122 were female. Two hundred thirty-six individuals were born in the US. The average age was 22 years and ranged from 20 to 33 . Two hundred fifty users (out of 266 users) identified themselves as frequent users of Facebook. In the original study, ages ranged from 18 to 25, and 52 out of 109 were female (Table 5). 


\begin{tabular}{|l|l|l|l|l|}
\hline \multicolumn{5}{|c|}{ Table 5. Comparing Demographic Information (Original and Replication) } \\
\hline & Male & Female & Age AVG & Age Range \\
\hline Original & 57 & 52 & - & $18-25$ \\
\hline Replication & 144 & 122 & 22 & $20-33$ \\
\hline
\end{tabular}

\subsection{Manipulation Checks}

The original study manipulates network commonality and information dissemination through a mockup version of Facebook. Similarly, in our study, we implement the manipulations via the text in each of the scenarios as depicted by Figure 2. As mentioned, in our study we used the same threshold used for high and low network commonality as in the original study in Southeast Asia.

\section{Please read the following paragraph carefully. Imagine the following scenario is real, and put yourself in the} described situation.

You attend class in a large lecture theater. You have not slept well over the last couple of nights and are feeling very drowsy during the lecture. At some point you actually fall asleep and are woken up after your head loudly hits your desk.

Sam who is a friend of yours, is also in the lecture theater and has posted a short note about the incident on his Facebook account. Sam and you are friends on Facebook and have $\mathbf{6 5}$ mutual friends; meaning that you have 65 friends in common on this particular online platform.

Since Sam has tagged you in the post, you learn about it through a notification on the Facebook platform. By tagging you, Sam has included a clickable hyperlink that allows anyone who sees this post to your access your Facebook profile page.

Sam's post reads:

I was sitting somewhere in the middle of the lecture theatre just now. After about 30 minutes of lecture, I started to feel really tired and begun stretching my neck. While turning my head around for the stretch, I somehow realized Danny was also in the LT! I was thinking that he was also doing some neck stretches, but I was wrong! I realized he was actually falling asleep and jerking his head left and right. Besides jerking his head around, he was dripping saliva from his mouth! Then out of a sudden, he banged his head onto the desk! It was a really hard hit and the whole LT was shocked by the BANG sound! I am sure it wakes you up for the rest of the lecture yeah? Lolx:p

This is a screenshot of what you see in your Facebook feed:

Figure 2. Example snapshot of sleeping scenario in our online survey along with corresponding manipulations for information dissemination (posting with tagging) and network commonality (high network commonality 65 mutual friends).

In addition, to match the original setting, we show a mock version of the Facebook pages in our online survey. Figures 3 and 4 illustrate the mockup pages as well as the corresponding manipulations for information dissemination and network commonality (red rectangles). 


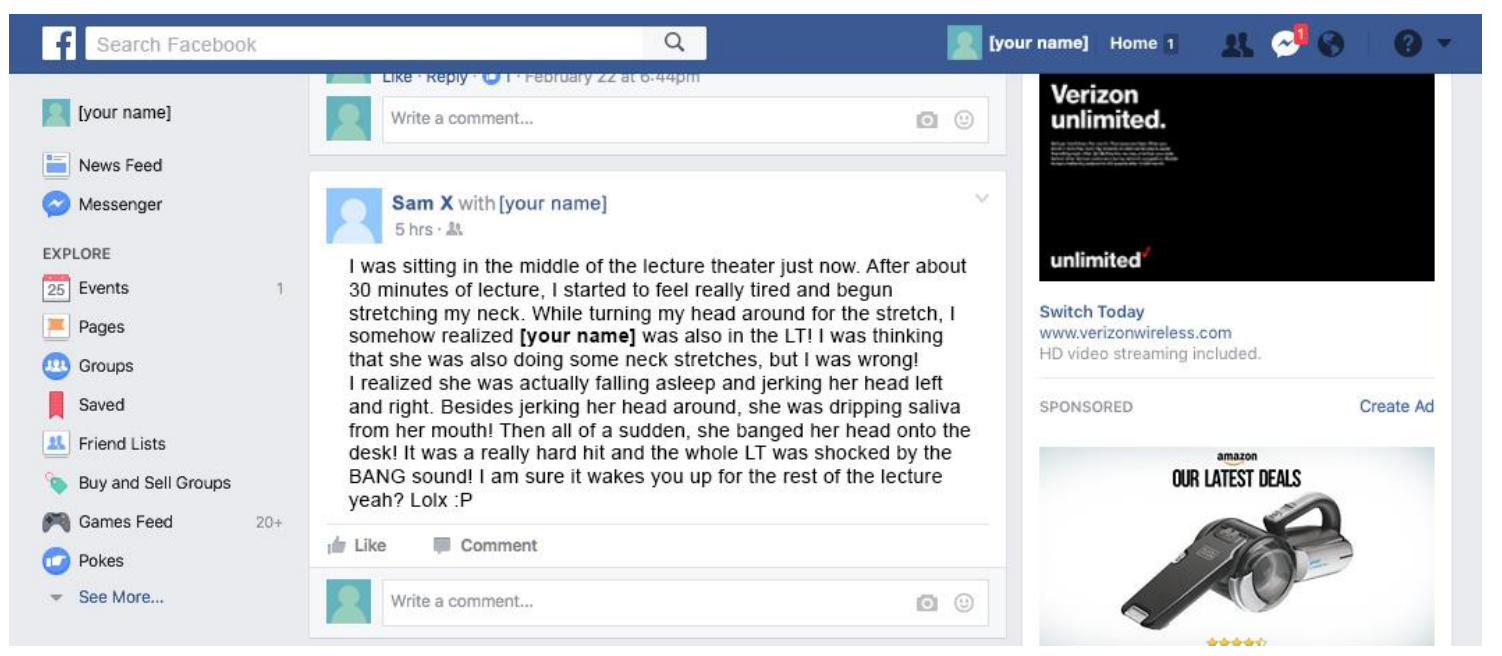

Figure 3. Facebook mockup page for sleeping and posting with tagging scenario.

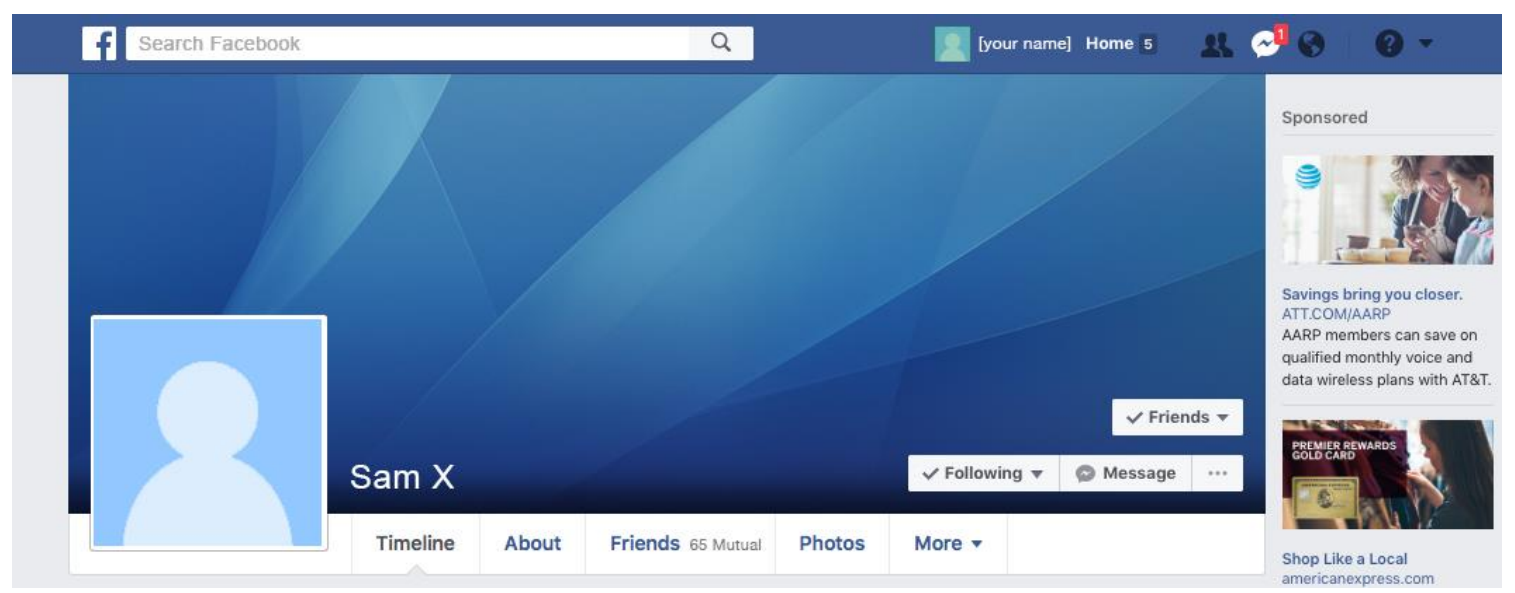

Figure 4. Facebook homepage mockup showing the number of mutual friends.

Consistent with the original study, the information dissemination manipulation was assessed by including three True/False items that asked the participant if she was aware that she had been tagged on the post or not. Twenty-four participants failed to identify whether they were tagged on the post and were dropped from the subsequent analysis. The network commonality manipulation check in the original paper was implemented by asking participants to rate how much their network overlapped with that of the presumed disseminator via a four-item scale. As in the original study, we used the same manipulation check items and we calculated the mean responses to verify the effect of the manipulations.

The manipulation check for information dissemination is effective and consistent with the original study $(\mathrm{t}=$ $-16.99, p<0.001$ ) in the drinking scenario. However, this is not the case for network commonality. Table 6 presents side-by-side comparisons between the manipulation check results for network commonality in the original paper and the results from each scenario used in this study. 


\begin{tabular}{|c|c|c|c|c|}
\hline \multicolumn{5}{|c|}{ Table 6. Network Commonality Manipulation Check (Original and Replication) } \\
\hline & Mean & Std. Dev. & $\mathbf{t}$ & $p$ \\
\hline \multicolumn{5}{|l|}{ Original } \\
\hline High NC & 5.58 & 0.57 & -28.89 & $<0.01$ \\
\hline Low NC & 2.57 & 0.52 & & \\
\hline \multicolumn{5}{|c|}{ Drinking Scenario } \\
\hline High NC & 4.22 & 0.20 & 0.6643 & 0.5078 \\
\hline Low NC & 4.40 & 0.17 & & \\
\hline \multicolumn{5}{|c|}{ Sleeping Scenario } \\
\hline High NC & 4.45 & 0.20 & -1.8129 & 0.0723 \\
\hline Low NC & 3.95 & 0.18 & & \\
\hline
\end{tabular}

From the results, we conclude that although we used the same manipulations from the Choi et al.'s (2015) experiment, we failed to replicate the manipulation effect for network commonality in both drinking and sleeping scenarios. We believe that the failure to manipulate network commonality in our study is associated with the choice of cut-off values used in the original study as thresholds of high versus low number of mutual friends. Remember that these numbers are the operationalization of the extent to which the network of two individuals overlap (i.e., network commonality). Facebook usage differences between the USA and Southeast Asia might influence the perception of network commonalities. To show that different number of friends in the US was the reason for the failure of the manipulation check, we conducted two follow-up studies which will be covered in Section 4.

\subsection{Behavioral Response Coding}

Following the procedure described by Choi et al. (2015), we coded the private messages and public comments provided by the participants who chose to contact the disseminator in one of these ways. We followed their provided samples to code each message as transactional avoidance, interpersonal avoidance, or approach behaviors. Participants who decided to do nothing are reported as engaging in inaction behavior.

\subsection{Measurement Reliability and Validity}

We assessed the internal consistency of Perceived Privacy Invasion and Perceived Relationship Bonding by calculating Cronbach's alpha. The alpha coefficients for Perceived Privacy Invasion and Perceived Relationship Bonding are 0.84 and 0.86 respectively, which confirms the reliability of both constructs. Consistent with the original study, we performed an exploratory factor analysis on the perceived privacy invasion and perceived relationship bonding items. We observed consistent loading on the perceived relationship bonding construct. However, there was not strong evidence that items for perceived privacy invasion completely load onto a single factor. We argue that the items used in the original study for measuring perceived privacy invasion might not be adequate to ensure construct validity. The four items were borrowed from Fusilier and Hoyer (1980) and Alge (2001) used in the original study are as follows:

1. I feel comfortable with the note about me being made public in this way.

2. I feel $X$ needs to exercise greater controls to limit this kind of note publication.

3. I feel that the note is none of anybody's business but my own.

4. I feel my exposure in the note was an invasion of my privacy.

These two studies investigate privacy invasion in the context of personnel selection and computer surveillance, which might not be completely generalizable to the context of privacy invasion in online social networks. It is possible that privacy invasion in online social networks is different from a surveillance camera situation in the sense that users are already willing to intentionally share some information with others. The failure to load in this context seem to suggest that the scale measures two different constructs. Overall, since the low construct validity for perceived privacy invasion might affect the overall validity of the tests, we believe this issue could be subject for further analysis in future studies. With this noted, we conduct the analysis of our study as assuming the validity of perceived privacy invasion. 


\subsection{Control Variables}

We calculate the correlation matrix for drinking and sleeping stimuli as well as the entire sample to assess the pairwise correlations between variables (shown in Table 7). Even though most of the correlation results match with that of the original paper, we found that in our data that the correlation between gender and personal relationship bonding is significant. Similarly, there is a significant correlation between Dispositional Privacy Concerns (DPC) and behavioral outcomes. Moreover, we see that 'Age' and 'US nationality' also has a significant correlation with Perceived Relationship Bonding and Perceived Privacy Invasion, respectively. This suggests that cultural differences could influence the perception of social exchanges. Nonetheless, the correlations stated above are relatively low (all under 0.4 ) and should not significantly influence the rest of the results. It is worth mentioning that due to our replication study being distributed as an online survey to our participants, measuring the control variables a week in advance as in the original study was not possible. Therefore, we collected perceptual controls in the post survey along with the demographics.

\begin{tabular}{|c|c|c|c|c|c|c|c|c|c|c|c|c|c|c|c|}
\hline \multicolumn{16}{|c|}{ Drinking stimulus } \\
\hline & Gen & Race & US & Age & FUI & DPC & so & NC & ID & PPI & PRB & IN & TA & IA & AP \\
\hline Gen & 1.00 & & & & & & & & & & & & & & \\
\hline Race & .01 & 1.00 & & & & & & & & & & & & & \\
\hline US & -.06 & $.47^{*}$ & 1.00 & & & & & & & & & & & & \\
\hline Age & .15 & -.07 & $-.33^{*}$ & 1.00 & & & & & & & & & & & \\
\hline FÜl & -.04 & .17 & .14 & -.14 & 1.00 & & & & & & & & & & \\
\hline DPC & -.07 & -.16 & .03 & -.05 & .08 & 1.00 & & & & & & & & & \\
\hline So & -.03 & .14 & .13 & -.15 & $.42^{*}$ & -.05 & 1.00 & & & & & & & & \\
\hline NC & .05 & -.05 & .09 & -.02 & -.16 & $.2251^{*}$ & .05 & 1.00 & & & & & & & \\
\hline ID & .01 & -.01 & .02 & -.12 & -.02 & .01 & .08 & .01 & 1.00 & & & & & & \\
\hline PPI & $-.27^{\star}$ & .03 & .02 & .03 & $.2619^{*}$ & $.28^{*}$ & .02 & -.07 & .03 & 1.00 & & & & & \\
\hline PRB & $.37^{*}$ & -.09 & -.06 & -.11 & -.16 & -.10 & .10 & .14 & .02 & $-.6250^{*}$ & 1.00 & & & & \\
\hline IN & .08 & .01 & .04 & -.02 & -.12 & $-.20^{*}$ & .04 & .02 & -.01 & $-.39^{*}$ & $.21^{*}$ & 1.00 & & & \\
\hline TA & -.14 & .01 & .08 & -.03 & .13 & .17 & .02 & .05 & .04 & $.30^{*}$ & $-.20^{*}$ & $-.5882^{\star}$ & 1.00 & & \\
\hline IA & $-.37^{*}$ & .03 & .02 & -.07 & .12 & .16 & \begin{tabular}{|l}
-.17 \\
\end{tabular} & -.07 & 0 & $.32^{*}$ & $-.38^{\star}$ & $\mid-.11$ & -.07 & 1.00 & \\
\hline AP & .07 & -.05 & .09 & -.09 & -.09 & -.09 & -.04 & .06 & .13 & $-.20^{\star}$ & $.26^{*}$ & -.02 & $-.31^{*}$ & $\mid-.01$ & 1.00 \\
\hline \multicolumn{16}{|c|}{ Sleeping stimulus } \\
\hline \multicolumn{16}{|c|}{\begin{tabular}{|l|l|} 
Gen & 1.00 \\
\end{tabular}} \\
\hline Race & -.03 & 1.00 & & & & & & & & & & & & & \\
\hline US & .08 & $.31^{*}$ & 1.00 & & & & & & & & & & & & \\
\hline Age & $.20^{*}$ & .03 & .07 & 1.00 & & & & & & & & & & & \\
\hline FÜI & -.14 & .05 & .07 & .05 & 1.00 & & & & & & & & & & \\
\hline DPC & .14 & -.06 & -.06 & .09 & -.09 & 1.00 & & & & & & & & & \\
\hline so & .13 & .16 & -.02 & .03 & $.38^{*}$ & .10 & 1.00 & & & & & & & & \\
\hline NC & -.11 & -.09 & -.03 & .09 & -.05 & .07 & -.02 & 1.00 & & & & & & & \\
\hline ID & -.10 & $-.21^{*}$ & -.12 & -.09 & $\mid .02$ & -.10 & \begin{tabular}{|l|}
.04 \\
\end{tabular} & .02 & 1.00 & & & & & & \\
\hline PPI & $-.20^{*}$ & -.03 & $-.17^{*}$ & $-.24^{*}$ & -.03 & $.21^{*}$ & -.16 & .10 & .08 & 1.00 & & & & & \\
\hline PRB & $.21^{*}$ & .03 & .11 & $.21^{*}$ & -.05 & -.06 & .15 & .13 & .02 & $-.63^{*}$ & 1.00 & & & & \\
\hline IN & .01 & .02 & -.08 & -.08 & -.09 & 0 & -.08 & -.04 & -.05 & -.02 & -.04 & 1.00 & & & \\
\hline TA & -.06 & .06 & .04 & -.04 & -.02 & $.27^{*}$ & -.05 & -.02 & -.04 & $.45^{*}$ & $-.31^{*}$ & $-.36^{*}$ & 1.00 & & \\
\hline IA & -.04 & -.13 & -.11 & -.02 & -.03 & .05 & -.11 & .05 & .10 & $.25^{*}$ & $-.28^{\star}$ & 0 & -.03 & 1.00 & \\
\hline AP & -.05 & -.11 & 0 & \begin{tabular}{|l}
.02 \\
.15 \\
\end{tabular} & .15 & -.15 & $.2049^{*}$ & $\star .03$ & -.06 & $-.55^{\star}$ & $.50^{*}$ & -.12 & $-.49^{*}$ & $-.30^{*}$ & 1.00 \\
\hline \multicolumn{16}{|c|}{$n=136$} \\
\hline \multicolumn{16}{|c|}{$\begin{array}{l}\text { US=born in US; } A G E=\text { age; } \mathrm{GEN}=\text { gender; } \mathrm{DPC}=\text { dispositional privacy concerns; } \mathrm{SOC}=\text { sociability; } \mathrm{FUI}=\mathrm{Facebook} \\
\text { usage experience; ID = information dissemination; } \mathrm{NM}=\text { network mutuality; } \mathrm{PPI}=\text { perceived privacy invasion; } \mathrm{PRB}= \\
\text { perceived relationship bonding; IN = inaction; } \mathrm{TA}=\text { transactional avoidance; } \mathrm{IA}=\text { interpersonal avoidance; } \mathrm{AP}= \\
\text { approach. }{ }^{*} \mathrm{p}<0.05,{ }^{* *} \mathrm{p}<0.01 \text {. Light shaded cells show the correlation matched to the original work. Dark shaded } \\
\text { cells denote the significant correlations exist in our dataset but not in the original study. Zero before the decimal point } \\
\text { was removed in the interest of saving space. }\end{array}$} \\
\hline
\end{tabular}


Consistent with Choi et al. (2015), we analyze the effect of individuals' characteristics including Dispositional Privacy Concerns (DPC), Sociability (SOC), and Facebook Usage Intensity (FUI) on behavioral responses using logistic regression. Table 8 shows the side-by-side results of logistic regression on behavioral responses (i.e., inaction, transactional avoidance, interpersonal avoidance, and approach) for the original, drinking, and sleeping scenarios. Results show that in both conditions Dispositional Privacy Concerns has significant effects on behavioral outcomes, unlike in the original study which reports non-significant effects from all control variables. Additionally, Sociability has a significant effect on approach behaviors especially in the sleeping condition $(\beta=0.49, p=0.038)$, which is different from the original study.

\begin{tabular}{|c|c|c|c|c|}
\hline & & Depend & Variables & \\
\hline \multicolumn{5}{|c|}{ Original Study } \\
\hline & Model A & Model B & Model C & Model D \\
\hline \multicolumn{5}{|l|}{ Covariates } \\
\hline \multicolumn{5}{|c|}{ Dispositional Privacy Concerns } \\
\hline Estimate & 0.06 & 0.05 & 0.44 & 0.06 \\
\hline Significance & 0.79 & 0.82 & 0.13 & 0.83 \\
\hline $95 \% \mathrm{Cl}$ & $(0.69,1.64) \dagger$ & $(-0.38,0.48)$ & $(-0.12,1.01)$ & $(-0.51,0.64)$ \\
\hline \multicolumn{5}{|l|}{ Sociability } \\
\hline Estimate & -0.24 & -0.54 & 0.14 & -0.57 \\
\hline Significance & 0.35 & 0.08 & 0.65 & 0.07 \\
\hline $95 \% \mathrm{Cl}$ & $(0.47,1.30) \dagger$ & $(-1.04,-0.05) \dagger$ & $(-0.47,0.76)$ & $(-1.19,0.05)$ \\
\hline \multicolumn{5}{|c|}{ Facebook Usage Intensity } \\
\hline Estimate & 0.23 & -0.24 & -0.43 & -0.54 \\
\hline Significance & 0.44 & 0.41 & 0.23 & 0.24 \\
\hline $95 \% \mathrm{Cl}$ & $(0.71,2.23) \dagger$ & $(-0.81,0.33)$ & $(-1.11,0.26)$ & $(-1.46,0.37)$ \\
\hline \multicolumn{5}{|c|}{ Replication Study: Drunk } \\
\hline & Model A & Model B & Model C & Model D \\
\hline \multicolumn{5}{|l|}{ Covariates } \\
\hline \multicolumn{5}{|c|}{ Dispositional Privacy Concerns } \\
\hline Estimate & -0.46 & 0.39 & 0.26 & -0.34 \\
\hline Significance & $0.035^{\star *}$ & $0.034^{\star *}$ & 0.16 & 0.19 \\
\hline $95 \% \mathrm{Cl}$ & $(-0.88,-0.32)$ & $(0.03,0.75)$ & $(-0.11,0.63)$ & $(-0.84,0.17)$ \\
\hline \multicolumn{5}{|l|}{ Sociability } \\
\hline Estimate & 0.03 & -0.04 & -0.27 & -0.31 \\
\hline Significance & 0.93 & 0.86 & 0.17 & 0.30 \\
\hline $95 \% \mathrm{Cl}$ & $(0.54,0.60)$ & $(-0.48,-0.40)$ & $(-0.67,0.12)$ & $(0.90,0.28)$ \\
\hline \multicolumn{5}{|c|}{ Facebook Usage Intensity } \\
\hline Estimate & -0.17 & -0.1 & 0.54 & 0.25 \\
\hline Significance & 0.68 & 0.77 & 0.08 & 0.61 \\
\hline $95 \% \mathrm{Cl}$ & $(-0.71,0.63)$ & $(-0.74,0.55)$ & $(-0.06,1.14)$ & $(-0.72,1.23)$ \\
\hline \multicolumn{5}{|c|}{ Replication Study: Sleep } \\
\hline \multirow{2}{*}{\multicolumn{5}{|c|}{ Covariates }} \\
\hline & & & & \\
\hline \multicolumn{5}{|c|}{ Dispositional Privacy Concerns } \\
\hline Estimate & -0.01 & 0.60 & 0.14 & -0.51 \\
\hline Significance & 0.92 & $0.002^{\star *}$ & 0.52 & $0.002^{\star \star \star}$ \\
\hline $95 \% \mathrm{Cl}$ & $(-0.30,0.27)$ & $(0.22,0.99)$ & $(-0.29,0.58)$ & $(-0.82,-0.19)$ \\
\hline \multicolumn{5}{|l|}{ Sociability } \\
\hline Estimate & -0.04 & -0.35 & -0.52 & 0.49 \\
\hline Significance & 0.88 & 0.16 & 0.084 & $0.038^{\star *}$ \\
\hline $95 \% \mathrm{Cl}$ & $(-0.48,0.41)$ & $(-0.83,0.14)$ & $(-1.11,0.07)$ & $(0.03,0.95)$ \\
\hline \multicolumn{5}{|c|}{ Facebook Usage Intensity } \\
\hline Estimate & -0.35 & 0.13 & -0.20 & 0.13 \\
\hline Significance & 0.22 & 0.67 & 0.59 & 0.64 \\
\hline $95 \% \mathrm{Cl}$ & $(-0.97,0.63)$ & $(-0.46,0.71)$ & $(-3.78,6.62)$ & $(-0.41,0.67)$ \\
\hline \multicolumn{5}{|c|}{$\begin{array}{l}\text { Model A: DV = Inaction, } \\
\text { Model B: DV = Transactional Avoidance, } \\
\text { Model C: DV = Interpersonal Avoidance, } \\
\text { Model D: DV Approach } \\
\text { t: As is in the original figure on online sup }\end{array}$} \\
\hline
\end{tabular}




\subsection{Effects on Perceived Privacy Invasion and Perceived Relationship Bonding}

Following the approach from the original study, we compare the means for each condition and present the side-by-side comparisons in Table 9.

\begin{tabular}{|c|c|c|c|c|c|c|c|}
\hline \multicolumn{4}{|c|}{ Perceived Privacy Invasion } & \multicolumn{4}{|c|}{ Perceived Relationship Bonding } \\
\hline & & LNC & HNC & & & LNC & HNC \\
\hline \multirow{3}{*}{$\mathrm{PO}$} & Original & 3.66 & 5.23 & \multirow{3}{*}{ PO } & Original & 4.21 & 3.79 \\
\hline & Drunk & $\begin{array}{ll}5.73 \\
(0.90) \\
\end{array}$ & $\begin{array}{l}5.56 \\
(0.92)\end{array}$ & & Drunk & $\begin{array}{l}2.32 \\
(1.01)\end{array}$ & $\begin{array}{l}2.27 \\
(1.02)\end{array}$ \\
\hline & Sleep & \begin{tabular}{|l|}
4.52 \\
$(1.31)$
\end{tabular} & $\begin{array}{l}4.34 \\
(1.05)\end{array}$ & & Sleep & $\begin{array}{l}3.17 \\
(1.05)\end{array}$ & $\begin{array}{l}3.37 \\
(0.75)\end{array}$ \\
\hline \multirow{3}{*}{ PwT } & Original & 5.81 & 5.39 & \multirow{3}{*}{ PwT } & Original & 2.59 & 5.56 \\
\hline & Drunk & $\begin{array}{l}5.71 \\
(1.09) \\
\end{array}$ & $\begin{array}{l}5.71 \\
(0.90)\end{array}$ & & Drunk & $\begin{array}{l}2.49 \\
(1.12)\end{array}$ & $\begin{array}{l}2.52 \\
(1.00) \\
\end{array}$ \\
\hline & Sleep & \begin{tabular}{|l|}
4.39 \\
$(1.36)$
\end{tabular} & $\begin{array}{l}4.77 \\
(1.12)\end{array}$ & & Sleep & $\begin{array}{l}3.29 \\
(1.33)\end{array}$ & $\begin{array}{l}3.19 \\
(1.09)\end{array}$ \\
\hline
\end{tabular}

As shown in the table, there appears to be no difference between means in each condition. Table 10 shows the results from the ANOVA analysis as performed in the original study. Results show no significant differences between conditions, which could be explained by the failure to replicate the manipulation of network commonality.

\begin{tabular}{|c|c|c|c|c|c|c|c|c|c|}
\hline \multicolumn{10}{|c|}{ Table 10. ANOVA Results (Original and Replication) } \\
\hline \multicolumn{10}{|c|}{ Perceived Privacy Invasion } \\
\hline & \multicolumn{3}{|c|}{ Type III sum of squares } & \multicolumn{3}{|l|}{$\mathbf{F}$} & \multicolumn{3}{|c|}{ Significance } \\
\hline & Orig. & Drunk & Sleep & Orig. & Drunk & Sleep & Orig. & Drunk & Sleep \\
\hline \multicolumn{10}{|c|}{ Overall sample } \\
\hline ID & 36.6 & 0.09 & 0.21 & 100.61 & 0.09 & 0.15 & 0.00 & 0.76 & 0.70 \\
\hline $\mathrm{NC}$ & 8.09 & 0.17 & 0.62 & 22.24 & 0.19 & 0.42 & 0.00 & 0.66 & 0.52 \\
\hline $\mathrm{ID} \times \mathrm{NC}$ & 27.45 & 0.00 & 2.31 & 75.47 & 0.00 & 1.57 & 0.00 & 0.95 & 0.21 \\
\hline \multicolumn{10}{|l|}{$\mathrm{NC}=$ Low } \\
\hline ID & 64.35 & 0.09 & 0.21 & 151.69 & 0.09 & 0.12 & 0.00 & 0.76 & 0.73 \\
\hline \multicolumn{10}{|c|}{$\mathrm{NC}=\mathrm{High}$} \\
\hline ID & 0.33 & 0.13 & 2.58 & 1.08 & 0.14 & 2.34 & 0.31 & 0.71 & 0.13 \\
\hline \multicolumn{10}{|c|}{ Perceived Relationship Bonding } \\
\hline & \multicolumn{3}{|c|}{ Type III sum of squares } & \multicolumn{3}{|l|}{$\mathbf{F}$} & \multicolumn{3}{|c|}{ Significance } \\
\hline & Orig. & Drunk & Sleep & Orig. & Drunk & Sleep & Orig. & Drunk & Sleep \\
\hline \multicolumn{10}{|c|}{ Overall sample } \\
\hline ID & 4.87 & 0.00 & 0.65 & 8.69 & 0.00 & 0.54 & 0.00 & 1.00 & 0.46 \\
\hline NC & 85.98 & 0.26 & 1.09 & 153.43 & 0.23 & 0.90 & 0.00 & 0.63 & 0.34 \\
\hline $\mathrm{ID} \times \mathrm{NC}$ & 38.66 & 0.51 & 1.07 & 68.99 & 0.47 & 0.89 & 0.00 & 0.50 & 0.35 \\
\hline \multicolumn{10}{|l|}{$\mathrm{NC}=$ Low } \\
\hline ID & 35.83 & 0.00 & 0.65 & 52.52 & 0.00 & 0.49 & 0.00 & 1.00 & 0.49 \\
\hline \multicolumn{10}{|c|}{$\mathrm{NC}=\mathrm{High}$} \\
\hline ID & 7.97 & 0.97 & 0.45 & 18.26 & 0.88 & 0.43 & 0.00 & 0.35 & 0.52 \\
\hline
\end{tabular}

\subsection{Effects on Behavioral Responses}

We conduct the analysis for the behavioral responses in a way that is consistent with Choi et al. (2015) and the results are available for comparison in Table 11. For inaction behavior, represented in Model A, we used a simple logistic regression and show that for the drinking scenarios our results replicate those of the original 
study, but not in the sleeping scenario. The rest of the behaviors were analyzed using ordered logistic regression and were, in general, consistent with the original study (in both significance and directionality). Although the manipulation for network commonality failed to replicate in our study, we see similar effects of the endogenous variable on the behavioral responses provided by the participants.

\begin{tabular}{|c|c|c|c|c|c|c|c|c|c|}
\hline \multirow{2}{*}{\multicolumn{10}{|c|}{$\begin{array}{l}\text { Table 11. Behavioral Response Resı } \\
\text { Dependent Variable }\end{array}$}} \\
\hline & & & & & & & & & \\
\hline \multicolumn{10}{|l|}{ Original Study } \\
\hline \multicolumn{10}{|c|}{\begin{tabular}{|l|l|l|} 
Model A & Model B \\
\end{tabular}} \\
\hline Threshold & & $\mathrm{TA}=0$ & $\mathrm{TA}=1$ & $\mathrm{TA}=2$ & $\mathrm{IA}=0$ & $\mathrm{IA}=1$ & $\mathrm{IA}=2$ & $\mathrm{AP}=0$ & $\mathrm{AP}=1$ \\
\hline Estimate & & 2.29 & 3.78 & 5.25 & 2.34 & 2.96 & 5.11 & 3.46 & 4.18 \\
\hline Standard Error & & 1.16 & 1.21 & 1.3 & 0.35 & 0.41 & 0.95 & 0.89 & 0.92 \\
\hline Significance (P-value) & & $<.05$ & $<.01$ & $<.01$ & $<.01$ & $<.01$ & $<.01$ & $<.01$ & $<.01$ \\
\hline \multicolumn{10}{|l|}{ Predictors } \\
\hline \multicolumn{10}{|c|}{ Perceived Privacy Invasion } \\
\hline Estimate & -0.78 & & 2.9 & & & 0.71 & & \multicolumn{2}{|c|}{-1.17} \\
\hline Standard Error & 0.3 & & 0.58 & & & 0.36 & & \multicolumn{2}{|c|}{0.78} \\
\hline Significance & $<.01$ & & $<.01$ & & & 0.23 & & \multicolumn{2}{|c|}{$<.05$} \\
\hline \multicolumn{10}{|c|}{ Perceived Relationship Bonding } \\
\hline Estimate & -1.45 & & $\mid-0.62$ & & & -1.01 & & \multicolumn{2}{|c|}{3.24} \\
\hline Standard Error & 0.31 & & 0.23 & & & 0.32 & & \multicolumn{2}{|c|}{0.78} \\
\hline Significance (P-value) & $<.01$ & & $<.01$ & & & $<.05$ & & \multicolumn{2}{|c|}{$<.01$} \\
\hline \multicolumn{10}{|c|}{ Replication: Drunk Scenario } \\
\hline & \multicolumn{3}{|c|}{\begin{tabular}{|l|l|} 
Model A & Model B
\end{tabular}} & \multicolumn{3}{|c|}{ Model C } & \multicolumn{3}{|l|}{ Model D } \\
\hline Threshold & & $\mathrm{TA}=0$ & $\mathrm{TA}=1$ & $\mathrm{IA}=0$ & $\mid A=1$ & $\mathrm{IA}=2$ & $\mathrm{AP}=0$ & $\mathrm{AP}=1$ & $\mathrm{AP}=2$ \\
\hline Estimate & & -1.01 & 4.33 & 0.84 & 2.19 & 3.52 & 2.54 & 4.18 & 5.3 \\
\hline Standard Error & & 0.21 & 0.72 & 0.23 & 0.3 & 0.45 & 0.37 & 0.64 & 1.04 \\
\hline Significance (P-value) & & $<.001$ & $<.001$ & $<.001$ & $<.001$ & $<.001$ & $<.001$ & $<.001$ & $<.001$ \\
\hline \multicolumn{10}{|l|}{ Predictors } \\
\hline \multicolumn{10}{|c|}{ Perceived Privacy Invasion } \\
\hline Estimate & -1.12 & & 0.66 & & 0.5 & & & -0.4 & \\
\hline Standard Error & 0.34 & & 0.25 & & 0.29 & & & 0.34 & \\
\hline Significance (P-value) & $<.001$ & & .01 & & 0.087 & & & 0.24 & \\
\hline \multicolumn{10}{|c|}{ Perceived Relationship Bonding } \\
\hline Estimate & -0.11 & & -0.03 & & -0.8 & & & 0.6 & \\
\hline Standard Error & 0.33 & & 0.25 & & 0.31 & & & 0.35 & \\
\hline Significance (P-value) & 0.74 & & 0.9 & & .009 & & & 0.09 & \\
\hline \multicolumn{10}{|c|}{\begin{tabular}{|l|l|} 
Replication: Sleeping Scenario \\
\end{tabular}} \\
\hline & Model A & Model B & Model & & & Model I & & & \\
\hline Threshold & & - & $\mid A=0$ & $\mid A=1$ & $\mathrm{IA}=2$ & $\mathrm{AP}=0$ & $\mathrm{AP}=1$ & $\mathrm{AP}=2$ & $\mathrm{AP}=3$ \\
\hline Estimate & & - & 2.37 & 4.13 & 5.56 & -0.03 & 2.07 & 4.12 & 5.98 \\
\hline Standard Error & & - & 0.37 & 0.59 & 1.05 & 0.21 & 0.28 & 0.5 & 1.04 \\
\hline Significance (P-value) & & - & $<.001$ & $<.001$ & $<.001$ & 0.89 & $<.001$ & $<.001$ & $<.001$ \\
\hline \multicolumn{10}{|l|}{ Predictors } \\
\hline Perceived Privacy Inva & & & & & & & & & \\
\hline Estimate & -0.18 & - & & 0.82 & & & & -1.19 & \\
\hline Standard Error & 0.24 & - & & 0.42 & & & & 0.25 & \\
\hline Significance (P-value) & 0.45 & - & & 0.051 & & & & $<.001$ & \\
\hline Perceived Relationship & & & & & & & & & \\
\hline Estimate & -0.21 & - & & -0.55 & & & & 0.47 & \\
\hline Standard Error & 0.24 & - & & 0.4 & & & & 0.24 & \\
\hline Significance (P-value) & 0.38 & - & & 0.17 & & & & 0.05 & \\
\hline
\end{tabular}




\subsection{Mediating Effect Analysis}

Consistent with the original study, we test for mediation effects of Perceived Privacy Invasion and Perceived Relationship Bonding between information dissemination and network commonality and output variables for each stimulus using the method proposed by (Baron \& Kenny, 1986). The result of mediation analysis is shown in Table 12. As shown in the table, even though the effect of PPI and PRB on outcome variables is almost significant, the relationships between the independent variables (i.e., information dissemination and network commonality) and intermediate variables (i.e., PPI and PRB) are not significant; most likely due to the failure to manipulate network commonality. Without Model 1 being significant in our study, we are not able to replicate the mediation effect for PPI and PRB.

\begin{tabular}{|c|c|c|c|c|c|c|c|c|c|c|}
\hline & Tabl & & Allal & & II an & my & V & ana & on) & \\
\hline Origina & Study & & & & & & & & & \\
\hline & Model 1 & & Model 2 & & & & Model 3 & & & \\
\hline & PPI & PRB & IN & IA & TA & AP & IN & IA & TA & AP \\
\hline ID & $0.45^{\star *}$ & $-0.58^{\star *}$ & $-1.52^{\star \star}$ & $1.58^{\star *}$ & $1.45^{*}$ & $-2.08^{\star \star}$ & $\begin{array}{l}-0.56 \\
(0.18)\end{array}$ & \begin{tabular}{|l|}
0.71 \\
$(0.27)$
\end{tabular} & $\begin{array}{l}0.09 \\
(0.91)\end{array}$ & \begin{tabular}{|l|}
-0.66 \\
$(0.48)$
\end{tabular} \\
\hline $\mathrm{NC}$ & $-1.99^{\star *}$ & $-0.25^{\star \star}$ & $-1.83^{* *}$ & $-1.62^{* *}$ & $-1.46^{*}$ & $1.49^{* *}$ & $\begin{array}{l}-.049 \\
(0.51)\end{array}$ & $\begin{array}{l}-1.24 \\
(0.18)\end{array}$ & \begin{tabular}{|l|}
-0.03 \\
$(0.98)$ \\
\end{tabular} & $\begin{array}{l}0.13 \\
(0.92)\end{array}$ \\
\hline PPI & & & & & & & $-0.77^{*}$ & $2.74^{\star *}$ & $\begin{array}{l}0.75 \\
(0.10)\end{array}$ & $-1.06^{*}$ \\
\hline PRB & & & & & & & $-1.38^{* \star}$ & $-0.57^{\star *}$ & $-0.98^{*}$ & $3.18^{\star \star}$ \\
\hline Replica & ion Study & Drunk S & enario & & & & & & & \\
\hline & Model 1 & & Model 2 & & & & Model 3 & & & \\
\hline & PPI & PRB & IN & IA & TA & $\mathrm{AP}$ & IN & IA & TA & $\mathrm{AP}$ \\
\hline ID & $\begin{array}{l}0.066 \\
(0.70)\end{array}$ & \begin{tabular}{|l|}
0.21 \\
$(0.26)$ \\
\end{tabular} & \begin{tabular}{|l|}
0.06 \\
$(0.31)$
\end{tabular} & $\begin{array}{l}0.04 \\
(0.78)\end{array}$ & $\begin{array}{l}-0.01 \\
(0.89)\end{array}$ & $\begin{array}{l}0.16^{*} \\
(0.05)\end{array}$ & $\begin{array}{l}0.078 \\
(0.19)\end{array}$ & $\begin{array}{l}0.084 \\
(0.56)\end{array}$ & $\begin{array}{c}-0.02 \\
(0.80)\end{array}$ & \begin{tabular}{|l|l|}
0.14 \\
$(0.07)$
\end{tabular} \\
\hline NC & $\begin{array}{l}0.10 \\
(0.56)\end{array}$ & $\begin{array}{l}0.01 \\
(0.95) \\
\end{array}$ & \begin{tabular}{|l|}
-0.10 \\
$(0.11)$ \\
\end{tabular} & $\begin{array}{l}-0.16 \\
(0.29) \\
\end{array}$ & $\begin{array}{l}0.057 \\
(0.51) \\
\end{array}$ & $\begin{array}{l}-0.03 \\
(0.69) \\
\end{array}$ & $\begin{array}{l}-0.08 \\
(0.16) \\
\end{array}$ & \begin{tabular}{|l|}
-0.17 \\
$(0.23)$ \\
\end{tabular} & $\begin{array}{l}0.04 \\
(0.61) \\
\end{array}$ & $\begin{array}{l}-0.03 \\
(0.71) \\
\end{array}$ \\
\hline PPI & & & & & & & $\begin{array}{l}-0.16^{\star \star \star} \\
(0.000) \\
\end{array}$ & \begin{tabular}{|l|}
0.13 \\
$(0.18)$ \\
\end{tabular} & $\begin{array}{l}0.151^{* *} \\
(0.008) \\
\end{array}$ & $\begin{array}{l}-0.04 \\
(0.44) \\
\end{array}$ \\
\hline PRB & & & & & & & $\begin{array}{c}-0.02 \\
(0.58)\end{array}$ & $\begin{array}{l}-0.24^{\star \star} \\
(0.007)\end{array}$ & $\begin{array}{l}-0.005 \\
(0.93)\end{array}$ & \begin{tabular}{|l|}
0.09 \\
$(0.08)$
\end{tabular} \\
\hline $\mathrm{n}$ & 130 & & 130 & & & & 130 & & & \\
\hline Replica & ion Study & Sleep S & enario & & & & & & & \\
\hline & Model 1 & & Model 2 & & & & Model 3 & & & \\
\hline & PPI & PRB & IN & IA & TA & AP & IN & IA & TA & AP \\
\hline ID & $\begin{array}{l}0.10 \\
(0.64)\end{array}$ & $\begin{array}{l}-0.003 \\
(0.1) \\
\end{array}$ & $\begin{array}{l}0.016 \\
(0.85)\end{array}$ & $\begin{array}{l}0.063 \\
(0.464)\end{array}$ & \begin{tabular}{|l|}
-0.036 \\
$(0.657)$
\end{tabular} & $\begin{array}{l}-0.228 \\
(0.153) \\
\end{array}$ & $\begin{array}{l}0.019 \\
(0.822) \\
\end{array}$ & \begin{tabular}{|l|}
0.058 \\
$(0.485)$ \\
\end{tabular} & $\begin{array}{l}-0.053 \\
(0.470) \\
\end{array}$ & $\begin{array}{l}-0.198 \\
(0.130) \\
\end{array}$ \\
\hline $\mathrm{NC}$ & $\begin{array}{l}-0.142 \\
(0.514) \\
\end{array}$ & \begin{tabular}{|l|}
-0.026 \\
$(0.893)$ \\
\end{tabular} & $\begin{array}{l}-0.0016 \\
(0.984) \\
\end{array}$ & $\begin{array}{l}-0.0075 \\
(0.930) \\
\end{array}$ & $\begin{array}{l}0.0206 \\
(0.800) \\
\end{array}$ & $\begin{array}{l}-0.0112 \\
(0.944) \\
\end{array}$ & $\begin{array}{l}-0.0074 \\
(0.929) \\
\end{array}$ & $\begin{array}{l}-0.0034 \\
(0.967) \\
\end{array}$ & $\begin{array}{l}0.0429 \\
(0.557) \\
\end{array}$ & $\begin{array}{l}-0.047 \\
(0.72) \\
\end{array}$ \\
\hline PPI & & & & & & & $\begin{array}{l}-0.033 \\
(0.442)\end{array}$ & \begin{tabular}{|l|}
0.046 \\
$(0.282)$
\end{tabular} & $\begin{array}{l}0.16^{\star * *} \\
(0.000)\end{array}$ & $\begin{array}{l}-0.29^{\star \star *} \\
(0.000)\end{array}$ \\
\hline PRB & & & & & & & $\begin{array}{l}-0.042 \\
(0.382)\end{array}$ & $\begin{array}{l}-0.090 \\
(0.057)\end{array}$ & $\begin{array}{l}-0.018 \\
(0.667)\end{array}$ & $\begin{array}{l}0.204^{\star \star} \\
(0.007)\end{array}$ \\
\hline $\mathrm{n}$ & & 36 & & & 36 & & & & 36 & \\
\hline $\begin{array}{l}\mathrm{PPI}=\mathrm{p} \\
\text { avoidan } \\
\text { Model } 1 \\
\text { Model } 2 \\
\text { Model } 3 \\
\mathrm{p} \text {-value }\end{array}$ & $\begin{array}{l}\text { Relations } \\
\text { Relations } \\
\text { Full mode } \\
\text { in parenth }\end{array}$ & $\begin{array}{l}\text { racy inva } \\
\text { rpersona } \\
\text { ips betwe } \\
\text { ips betwe } \\
\text { eses * } p<<\end{array}$ & $\begin{array}{l}\text { n; PRB = } \\
\text { voidance } \\
\text { n the inde } \\
\text { n the inde } \\
55,{ }^{* *} \mathrm{p}<0\end{array}$ & $\begin{array}{l}\text { eerceived } \\
\text { AP }=\text { app } \\
\text { endent va } \\
\text { endent va } \\
1,{ }^{* \star *} \mathrm{p}<\end{array}$ & $\begin{array}{l}\text { relationsh } \\
\text { oach. } \\
\text { riables ar } \\
\text { riables ar } \\
.001\end{array}$ & $\begin{array}{l}\text { bonding } \\
\text { mediatin } \\
\text { depende }\end{array}$ & $\begin{array}{l}N=\text { inacti } \\
\text { variables } \\
t \text { variables }\end{array}$ & $; \mathrm{TA}=$ & ctional & \\
\hline
\end{tabular}




\section{Follow-up Studies}

\subsection{Study 2: Facebook Friend Survey}

As addressed above, our first study attempted to replicate the original study almost exactly. We used the same scenario, same manipulation, and measured the same constructs. However, we were unable to replicate the original manipulation effect for network commonality. One of the reasons for this could be associated with the numbers associated with low and high network commonality. In the original study Choi et al. (2015) use 7 and 65 as their threshold numbers. However, it might be that for the United States in 2018 these numbers are not representative of low and high network commonality. This could be because of sheer differences in the use of Facebook between the times when the original study was conducted and even regional differences in use. According to top marketing research companies, the average number of Facebook friends in North America for people between 18 and 24 is 649 friends and for ages 25 to 34 their average number of friends is 360 (Edison Research; Triton Digital, 2014). To look deeper into this, we conducted a survey of 198 students aged between 20 and 33 (mean $=21.64$ years old). We asked our participants to "think about their Facebook account" and "provide your best estimate for how many friends you have on Facebook". The response was recorded on a slider item with minimum value of zero and maximum value of 1,000 . The average number of friends was 588.46 with a standard deviation of 306.95. We also wanted to know what students perceived as low and high network commonalities. To do this we asked participants to imagine they have a friend called Sam with which they have some number of "mutual friends". Then we used two items to record low and high network commonality perceptions. On one item we asked, "If your social network overlaps considerably with Sam's, what percentage of mutual friends would you expect to have with Sam?". Similarly, we asked "If your do not have many friends in common with Sam, what percentage of mutual friends would you expect to have with Sam?". These items were counterbalanced. The average number of mutual friends for the high commonality item was 49.71 percent of their total friends being mutual friends. The average number of mutual friends for the low commonality item was 12.58 percent of their total friends being mutual friends on Facebook. These results confirm that there is a significant difference between the average number of friends used to create the original thresholds (130 friends) and the average number of friends reported by our subject pool. If the average number of friends in this sample is 588 and the average percentage for a low network overlap is $12.58 \%$, then the low threshold should be 74 friends rather than 7 . Similarly, the high threshold should be 292 rather than 65.

\subsection{Study 3: Manipulation Evaluation}

Using the survey results we reevaluate the thresholds that should be used to effectively manipulate network commonality. To test whether a new set of thresholds would be enough to effectively manipulate network commonality, we conducted a follow-up study on a sample of 88 participants. The study is a 2 between by 2 within design. Half of the participants were randomly assigned to see a high network commonality manipulation $(n=42)$, while the rest saw the low network commonality manipulation $(n=46)$. The original study considers $5 \%$ and $50 \%$ of the average number of Facebook friends as low and high network commonality manipulations, respectively. Accordingly, we used a similar approach and rounded the numbers to scale our manipulations. As a result, we chose to use 20 mutual friends as the low network commonality manipulation and 250 as the high network commonality manipulation. All participants saw two scenarios in sequence, counterbalanced. One scenario was the original sleeping in lecture scenario. The other scenario was the drinking-based scenario introduced by us. As in the first study, the manipulation was presented in the body of the scenario's text.

After the participants read each scenario, they were asked to fill in the scales for perceived embarrassment and perceived relevance used in the original study. Next, the participants answered the manipulation check as in the original study, followed by the control variables measured in the first study.

The results from the independent sample T-test comparing the new thresholds for High $($ mean $=5.52)$ and Low $($ mean $=4.11)$ network commonality show a successful manipulation check $(t=5.22, p<0.01)$. These results are consistent with the manipulation checks in the original study. We were able to successfully manipulate network commonality by adjusting the thresholds. These results are summarized in Table 13. 


\begin{tabular}{|c|c|c|c|c|}
\hline \multicolumn{5}{|c|}{ Table 13. Scaled Manipulation Check for Network Commonality } \\
\hline & Mean & Std. Dev. & $t$ & $\mathbf{P}$ \\
\hline \multicolumn{5}{|c|}{ Original $(n=109)$} \\
\hline High NC & 5.58 & 0.57 & -28.89 & $<0.01$ \\
\hline Low NC & 2.57 & 0.52 & & \\
\hline \multicolumn{5}{|c|}{ Replication Follow-up Study $(n=88)$} \\
\hline High NC & 5.52 & 1.13 & 5.23 & $<0.01$ \\
\hline Low NC & 4.11 & 1.36 & & \\
\hline
\end{tabular}

The results of comparing our new scenario to the original scenario show that our drinking scenario is both significantly more embarrassing and more relevant to our sample than the sleeping scenario. This confirms our prediction that sleeping in lecture would not be as embarrassing or relevant to students in the United States. Table 14 shows the results of the two paired sample t-tests used to compare the perceived embarrassment and perceived relevance of each scenario.

\begin{tabular}{|l|l|l|l|l|l|}
\hline \multicolumn{7}{|l|}{ Table 14. Perceived Relevance and Embarrassment (Original and Replication Studies) } \\
\hline \multicolumn{7}{|l|}{ Mean } & Std. Dev. & t & p \\
\hline Variable: Perc. Embarrassment & 6.28 & 0.69 & & \\
\hline Original Study & 5.15 & 1.67 & 5.153 & $7.916 \mathrm{e}-07$ \\
\hline Drinking Scenario & 4.31 & 1.68 & & \\
\hline Sleeping scenario & 6.03 & 0.73 & & \\
\hline Variable: Perc. Relevance & 4.54 & 1.65 & 3.83 & 0.00012 \\
\hline Original Study & 3.91 & 1.60 & & \\
\hline Drinking Scenario &
\end{tabular}

\section{Discussion}

We approached the replication study using a methodological replication, maintaining as much of the original stimuli, scenarios, measures, and procedures as possible. We employed a survey experiment rather than a laboratory experiment but maintained the feel and flow of the experiment as close as possible to that of the original study. The decision to employ a survey experiment rather than a laboratory experiment was mainly to reach a broader sample of undergraduate students and to be able to test the additional scenario we included in this replication. The decision to add the new scenario was due to a concern we had about the degree to which getting caught sleeping in lecture would be perceived as embarrassing and relevant to US sample of undergraduate students.

Our study contributes to the extant literature by showing that there are possible effects of demographics on network commonality perceptions. Although the original manipulations were used in our study, we were not able to confirm the effect of the manipulation of network commonality with original cut-off values for low and high network commonality. Nevertheless, using the scaled threshold in our follow-up studies led to successful manipulation check. This is also a major factor that contributes to why the first step of the conceptual model did not replicate. A possible explanation for why we failed to replicate the network commonality is the difference in the use of the Facebook platform between the two regions in which the studies were conducted and the time difference between them. That is, students in the US could have a different view of a 'low' or 'high' number of common friends in their network due to a difference in how many friends they have and how much they use Facebook. The time difference factor is that the original study was run using data from 2010. During the time that passed between the two studies the use of Facebook has grown, and the number of total "friends" the users have has increased. The fact that we replicated the network commonality manipulation using vastly larger numbers than those used in the original paper suggests that network commonality, or at least its perception, could be significantly influenced by demographics as well as the passage of time.

Overall, almost all the effects on behavioral responses were replicated. We could replicate 8 hypotheses out of 12 hypotheses stated in the original study. Although, the manipulation of network commonality as 
used in original study was not successful in our study we still see replicated effects on the latter part of the conceptual model. From our follow-up studies we can see that by adapting the manipulation to match the current use of Facebook from US college students we are able to successfully manipulate network commonality. The results of the follow-up study suggest that replicating the main effects of network commonality on perceived privacy invasion and perceived relationship bonding could be achieved. Nevertheless, further research is encouraged to confirm that this is the case.

As shown earlier, unlike the original study, the effect of Dispositional Privacy Concern (DPC) is significant on Transactional Avoidance in both sleeping and drinking scenarios. Also, in the sleeping scenario, DPC has a significant effect on Approach. According to the original study, DPC reflects the extent to which a person is concerned about her privacy as a whole. The effect of DPC shows that some individuals do not consider their privacy as important as others do and this affects their behavioral response in exposure to an embarrassing situation. Similarly, Sociability (SOC) has significant effect on Interpersonal Avoidance and Approach. Sociability measures the extent to which a person tends to be sociable. The effect of SOC shows that people who are more sociable may react to the perception of privacy invasion differently than the ones who are not.

To address the aforementioned issue, we suggest enriching self-report measuring via questionnaire with observational network measures such as centrality and closeness. This can be realized by using visualization software packages that extract and visualize the network extraction of each individual in Facebook. The main benefit of this approach is that it provides a set of quantitative network characteristics that are less subjective and hence more independent from user's perception unlike network commonality. This can improve the model's generalizability while being applied in different contexts and on samples with different cultural backgrounds. However, it should be noted that psychological perceptions may not necessarily be aligned with social network statistics. That is, network statistics such as closeness and centrality may not reflect the perceptions individuals have in the real world. Therefore, this direction should be considered with caution and more in-depth studies.

We also found some interesting patterns that might open potential avenues for conducting future studies. Unlike in the original work, gender and age had a significant correlation with both endogenous variables (PPI and PRB). Sociability and Dispositional Privacy Concerns affected the behavioral responses in our study. These findings suggest that these variables should be given greater attention by researchers. Table 15 summarizes the result of this replication based on each hypothesis stated in (Choi et al., 2015).

\begin{tabular}{|l|l|l|}
\hline \multicolumn{2}{|c|}{ Table 15. Hypothesis Replication Summary } \\
\hline Hypothesis No. & Statement & $\begin{array}{l}\text { Status in } \\
\text { Replication Study }\end{array}$ \\
\cline { 1 - 2 } H1A & $\begin{array}{l}\text { Compared with posting only, posting with tagging will lead to a higher level of } \\
\text { perceived privacy invasion. }\end{array}$ & $\begin{array}{l}\text { Not able to replicate } \\
\text { with exact } \\
\text { thresholds of } \\
\text { manipulation as in } \\
\text { the original study. } \\
\text { However, the scaled } \\
\text { manipulation was } \\
\text { promising. } \\
\text { pommon in the low network commonality condition. }\end{array}$ \\
\hline H1B & $\begin{array}{l}\text { In the low network commonality condition, compared with posting only, posting } \\
\text { with tagging will lead to a lower level of perceived relationship bonding. }\end{array}$ \\
\hline H2A & $\begin{array}{l}\text { In the high network commonality condition, compared with posting only, } \\
\text { posting with tagging will lead to a higher level of perceived relationship } \\
\text { bonding. }\end{array}$ & Replicated \\
\hline H2B & Perceived privacy invasion will reduce the likelihood of inaction. & Replicated \\
\hline H3A & $\begin{array}{l}\text { Perceived privacy invasion will increase the likelihood of transactional } \\
\text { avoidance. }\end{array}$ & $\begin{array}{l}\text { Replicated } \\
\text { avoidance. }\end{array}$ \\
\hline H3B & Perceived privacy invasion will reduce the likelihood of approach behavior. & Replicated \\
\hline H3C & Perceived relationship bonding will reduce the likelihood of inaction. & Replicated \\
\hline H3D & $\begin{array}{l}\text { Perceived relationship bonding will reduce the likelihood of transactional } \\
\text { avoidance. }\end{array}$ & Replicated \\
\hline H4A & $\begin{array}{l}\text { Perceived relationship bonding will reduce the likelihood of interpersonal } \\
\text { avoidance. }\end{array}$ & Replicated \\
\hline H4B & $\begin{array}{l}\text { Perceived relationship bonding will increase the likelihood of approach } \\
\text { behavior. }\end{array}$ & Replicated \\
\hline H4C & &
\end{tabular}




\section{Conclusion}

This study aimed to assess the findings in Choi et al. (2015) on a larger sample size with US participants and additional embarrassing scenarios. Consistent with the original study, our findings showed that when people encounter an embarrassing situation in social media their perception of privacy and relationship bonding can significantly determine whether they approach the disseminator of the embarrassing post or engage in transactional and/or interpersonal avoidance with the disseminator. This has important business implications for software companies who host the social media platforms. Even though most of the proposed model was replicated and matched the original study, we observed that using the exact threshold for network commonality as in the original study, the effect of the network commonality on the endogenous variables (perceived privacy invasion and perceived relationship bonding) did not replicate. However, the manipulation was successful with scaled thresholds which account for the current Facebook use in the US. This finding signifies the necessity of further studies on how network commonality and its perception can be influenced by demographics, time, and location. Future research should incorporate these observational network measures and compare the validity and generalizability of the results to the original model that only contains network commonality. Given the prevalence of social media usage amongst individuals, this study opens more research opportunities to understand the role of privacy in social media.

\section{Acknowledgments}

We would like to thank Dr. Zhenhui Jiang, one of the original paper's authors, for being responsive to our questions. We would also like to thank Dr. Susan Brown for having constructive discussions throughout this study. 


\section{References}

Alge, B. J. (2001). Effects of computer surveillance on perceptions of privacy and procedural justice. Journal of Applied Psychology. 86(4):797-804.

Fusilier M. R., \& Hoyer W. D. (1980). Variables affecting perceptions of invasion of privacy in a personnel selection situation. Journal of Applied Psychology, 65(5):623-626.

Baron, R. M., \& Kenny, D. A. (1986). The moderator-mediator variable distinction in social psychological research: Conceptual, strategic, and statistical considerations. Journal of Personality and Social Psychology, 51(6), 1173-1182.

Choi, B. C. F., Jiang, Z. J., Xiao, B., \& Kim, S. S. (2015). Embarrassing exposures in online social networks: An integrated perspective of privacy invasion and relationship bonding. Information Systems Research, 26(4), 675-694.

Edison Research; Triton Digital. (2014, February). Average number of Facebook friends of users in the United States as of February 2014, by age group.

Internet World Stats. (2017, May). Facebook subscriber stats as of June 30, 2016. Facebook Users in the World.

Smith, N. (2013, April 26). How much is a Facebook friend worth? \$174.17. Business News Daily.

Wang, Y., Norcie, G., Komanduri, S., Acquisti, A., Leon, P., \& Cranor, L. (2011). I regretted the minute I pressed share: A qualitative study of regrets on Facebook. In Proceedings of the Seventh Symposium on Usable Privacy and Security. New York: ACM. 


\section{About the Authors}

Mohammadreza Ebrahimi is a doctoral student in the Department of Management Information Systems and a research associate at the Artificial Intelligence Lab, University of Arizona. He received his master's degree in Computer Science from Concordia University, Canada in 2016. His research interests include social media analytics, text mining, natural language processing, and machine learning. His work has appeared in journals and conferences such as Digital Forensics and Applied Artificial Intelligence, and IEEE ISI, as well as a book chapter in Data Mining Trends and Applications in Criminal Science and Investigations.

Daniel Martinez is a doctoral student from the Department of Marketing at the University of Arizona's Eller College of Management. He earned his Master's in Business Administration from the University of Texas at EI Paso in 2016. His research interests include news and social media management strategies, social media analytics, distribution channels, interfirm relationships, and empirical industrial organization.

Copyright @ 2019 by the Association for Information Systems. Permission to make digital or hard copies of all or part of this work for personal or classroom use is granted without fee provided that copies are not made or distributed for profit or commercial advantage and that copies bear this notice and full citation on the first page. Copyright for components of this work owned by others than the Association for Information Systems must be honored. Abstracting with credit is permitted. To copy otherwise, to republish, to post on servers, or to redistribute to lists requires prior specific permission and/or fee. Request permission to publish from: AIS Administrative Office, P.O. Box 2712 Atlanta, GA, 30301-2712 Attn: Reprints or via e-mail from ais@aisnet.org. 